Fecha de recepción: 09-10-2017

Fecha de aceptación: 29-01-2018

Link para este artículo: http://dx.doi.org/10.14198/ALEUA.2018.29-30.06

Puede citar este artículo como:

VARELA Olea, M ${ }^{a}$. Ángeles, «Julián Ayesta: Uuna joven promesa del TEU», Anales de Literatura Española, n. ${ }^{\circ}$ 29-30 (2018), pp. 133-160.

\title{
JULIÁN AYESTA: UNA JOVEN PROMESA DEL TEU
}

\author{
$\mathrm{M}^{\mathrm{a}}$. ÁNGELES VARELA OleA \\ Universidad San Pablo-CEU - CEU Universities
}

\section{Resumen}

Julián Ayesta fue uno de los escasos autores noveles representados por el TEU de Modesto Higueras. A esta singularidad se une el que fuese el primero y del único del que se representaron varias obras en los primeros años de la posguerra, cuando aún era un autor casi inédito. Son cuatro las obras que lo vinculan al grupo de Higueras: Simplemente así, El tímido Serafín, La ciudad lejana -en colaboración con A. Crespoy la traducción, luego prohibida, de El farsante del mundo occidental de Synge -en colaboración con Ch. D. Ley y R. Montesinos. La excepcionalidad de su caso corresponde con la de su carácter, de cuya genialidad damos algunos trazos testimoniales que también sirven para plasmar el bullicioso ambiente de la juventud creadora en la posguerra española. No en vano, Ayesta es el olvidado autor de una de las novelas más hermosas del s. XX: Helena o el mar de verano.

Palabras clave: Julián Ayesta, Teatro Español Universitario (TEU), Sindicato Español Universitario (SEU), posguerra española, juventud creadora.

\begin{abstract}
Julián Ayesta was one of the few young authors with his works played by the TEU (University Theater Group of Spain) of Modesto Higueras. In fact, three of his works were played by TEU: Simplemente así, El tímido Serafín, and La ciudad lejana -in collaboration with A. Crespo-; and he also made a version of The Playboy of the Western World, by J. M. Synge -in collaboration with Ch. D. Ley and R. Montesinos. In this essay, we analyze these works during his TEU's period and we also draw an outline of his brilliant character, adding some testimonial anecdotes that also serve to capture the bustling atmosphere of this creative youth in the Spanish post-war period. Finally, we conclude highlighting that Ayesta is the forgotten writer of one of the most striking Spanish novels in the 20th century: Helena o el mar de verano.
\end{abstract}

Keywords: Julián Ayesta, Teatro Español Universitario (TEU), Sindicato Español Universitario (SEU), Post-Civil War Period, Post-War Spanish young writers.

Anales, 29-30 (2018), pp. 133-160

DOI: 10.14198/ALEUA.2018.29-30.06 
Como es bien sabido, el repertorio de representaciones del Teatro Español Universitario (TEU) estaba compuesto sobre todo de comedias, entremeses y autos sacramentales del teatro clásico español, que durante la posguerra quedaron, así, al servicio del nuevo régimen (Huerta, 2006: 32-36). Los autores clásicos suponen la alternativa prestigiosa y consolidada al teatro comercial que esta iniciativa cultural desprecia, y cumplen, además, con la finalidad pedagógica y divulgativa propia de la Universidad, ya presente en su antecesor inmediato durante la II República, el grupo teatral universitario dirigido por Lorca, La Barraca.

Esa continuidad de la tradición clásica será un rasgo permanente desde sus inicios. Y así quedará explicitada en la revista del sindicato universitario, Haz, en el mismo 1941 en que José Miguel Guitarte -jefe nacional del SEUencomienda oficialmente a Modesto Higueras la creación de un TEU Nacional que fuera modelo de los existentes en las demás universidades. En el artículo de Haz, «Esfuerzo permanente del TEU», además de hacer el acostumbrado ataque al teatro comercial, señala cuáles son los objetivos de esta agrupación teatral:

[... dignificación de la escena española en la medida de sus fuerzas, llegar a compenetrar de una manera absoluta a la masa estudiantil con una de las vetas más ricas de la cultura hispánica e interrelacionar la clase popular española y la clase universitaria mediante recitales, representaciones, ensayos teatrales, etcétera.

[...] Mientras el teatro comercial llena la escena española de repugnantes engendros, a veces aplaudidos por una crítica rastrera y gacetilluda, el Teatro Español Universitario levanta su estandarte en toda la piel hispánica para recordar un pasado teatral espléndido y actualizar hermosamente ese pasado en representaciones contemporáneas llenas de respeto y amor (Bajo Martínez, 2015: 64 y 68, cit. Haz, no 33, 24 de junio, 1941, p. 7).

Esas mismas ideas reaparecerán con ocasión de las representaciones del TEU. A propósito del estreno de Simplemente así, de Julián Ayesta, acompañada de El cartero del rey de Rabindranath Tagore y Los borrachos de Quiñones de Benavente, Modesto Higueras responderá a Juan Carlos Villacorta -del periódico Arriba-, que la misión del TEU es «ser escuela de perfecciones espirituales, rebeldía frente al teatro comercial». Por lo que «Espero que nuestro teatro minoritario llegue a alcanzar con su influencia a la masa de espectadores desorientados». Eso mismo es lo que destaca Villacorta: la rebeldía del TEU, la urgencia del socorro ante la decadencia del teatro español «envenenado» por lo comercial y la importante función de estos jóvenes que pretenden arrebatárselo «de las manos de la codicia mercantil y la tacañería espiritual» (Arriba, 8-6-1943). 
Por eso, serán muy escasos los montajes de autores contemporáneos por parte del TEU, pues siendo pocas las representaciones que hacía y teniendo esa misión pedagógica, seleccionará preferentemente a autores consagrados como Marquina, Thorton Wilder, Álvarez Quintero, Jardiel Poncela, Mihura o Pemán. Y si el número de obras contemporáneas en el repertorio del TEU es proporcionalmente pequeño, aún más lo es el de quienes eran autores noveles, como es el caso del primero y más representado: Julián Ayesta. Pero también por eso, los autores seleccionados lo serán por esa rebeldía frente a lo comercial y decadente del teatro de posguerra. Ni siquiera será un criterio de selección un probado falangismo e identificación con el nacionalcatolicismo, puesto que en los encuentros de estos jóvenes y entre los montajes de Modesto Higueras está El celoso por infiel del conocido republicano bohemio Eusebio García Luengo; obra también publicada en el mismo número de Haz en que lo hacen otros noveles del TEU como Angulo, Crespo y Ayesta. ${ }^{1}$ José Gordón nos proporciona el nombre de únicamente cinco autores noveles de los que Modesto Higueras se aventuró a realizar los montajes: Víctor Ruiz Iriarte, José García Nieto, Eusebio García Luengo, Julio Angulo y Julián Ayesta (Gordón, 1965: 49). Ya en el siguiente lustro, de 1945 a 1950, habría que sumar los nombres de algunos autores que nos han llegado por la prensa como Faustino González Aller en colaboración con Rafael Montesinos, Vicente Escrivá en colaboración con Armando Ocano, o Lope Mateo (García Ruiz y Torres Nebrera, 2003: 53). ${ }^{2}$ Pero lo cierto es que la misión del TEU no era dar a conocer autores nuevos y si lo hacía era para mostrar la existencia de contemporáneos y noveles que aportaban una alternativa al teatro comercial que inundaba las carteleras.

Por todo ello, es especialmente significativa la temprana y más abundante representación que hizo el TEU de las obras de Julián Ayesta. En tanto que los autores mencionados más arriba estrenaron una o dos obras con él, Ayesta está vinculado al grupo de Modesto Higueras por cuatro obras que me detendré a analizar. Además, el primero de los montajes de una de sus obras, Simplemente así, debió de realizarse en 1943, lo cual supone una apuesta no sólo arriesgada

1. En la revista Haz coinciden casi todos los autores noveles de los primeros años del TEU. En marzo de 1943, el número 2 de la segunda época de Haz. Revista Nacional del SEU, bajo la dirección de Alberto Crespo (después coautor de La ciudad lejana, representada por el TEU), publica su artículo «A Cornelio Zalea Codreanu», Julio Angulo (autor de Ático izquierda, representada por el TEU) «La Universidad de Alcalá de Henares», Julián Ayesta publica su cuento «La República» y Eusebio García Luengo la obra representada por el TEU El celoso por infiel.

2. Un listado de autores y las obras representadas por el TEU más exhaustivo puede leerse en Manuel Gómez García, Un hombre de teatro. Modesto Higueras. El maestro y la asamblea, Madrid, Gráficas CARO, 2006, pp. 48-49. 
sino también temprana: a los dos años de que Modesto Higueras estuviese oficialmente a cargo del TEU Nacional y cuando lo único que había publicado Ayesta -que entonces sólo tenía veinticuatro años-, eran cuatro poemillas en la Antología del Alba de la Complutense y un cuento, «La República. Memorias de un joven burgués», en la mencionada revista nacional del SEU, Haz (en ellos me detendré más adelante). Sin duda, el joven Ayesta era ya conocido entre los estudiantes universitarios de Filosofía y Letras por esa genialidad con que sus contemporáneos lo describen, pero también por la peculiaridad de su pensamiento, por su posicionamiento antiburgués e inconformista y su pertenencia a la Falange. Siempre singular, siendo fiel a ese falangismo, en 1986 decía sin arrepentimientos que ese era el único partido al que se había afiliado en su vida y, como muestra de una particularidad ideológica común a amigos suyos como Dionisio Ridruejo, reconocía votar en la actualidad al PSOE, pues «potencialmente, lo que representaba la Falange en los años cuarenta es lo que hoy presenta el PSOE» (Alonso, 2013: 20).

\section{Ayesta: un genio efervescente}

Julián Ayesta (Gijón, 1919-1996) es uno de esos autores olvidados por las historiografías literarias y los grandilocuentes cánones, que no saben en qué marbete literario encajarlo (Paleologos, 2007: 1). Rara avis entre varias generaciones, entre varios géneros literarios, entre varios oficios, entre varias ideologías políticas; es un autor difícil de someter a clasificación. Y sin embargo, para sus contemporáneos, de García Nieto a Pere Gimferrer, era siempre un autor esperado, al que instaban para que reuniera una obra aún hoy en día dispersa ${ }^{3}$ y parcialmente inédita. Autor oral, frecuente en las tertulias -del café Fénix, del Gijón o del Ateneo-, que suponía «un espectáculo fantástico, hablaba por los codos, parlanchín, aventado, ingenioso y a veces, mudo». ${ }^{4}$ En su amenísima charla, llena de ingeniosidades, relataba a veces las historias que iba a escribir, la mayoría de las cuales nunca ponía por escrito: como aquella sobre los escritores del Gijón que se quejan constantemente de que no pueden

3. En 1973, cuando Ayesta vivía en Amsterdam, Pere Gimferrer le propone la publicación de su obra dispersa y aún inédita para la editorial Seix Barral. Carta fotografiada en Dibujos y poemas, editados por Antonio Pau (2003: 15). El mismo A. Pau ha reunido algunos de sus cuentos (Cuentos, Pre-textos, 2001) y sus cuatro poemas, varios artículos y dibujos en el otro volumen citado. Además, a Pau le debemos la más completa biografía existente del autor, incorporada como estudio preliminar a la edición de los cuentos «Julián Ayesta. El resplandor de la prosa», 2001: 9-119.

4. Testimonio personal de José Luis Varela, quien lo trató mucho hasta 1953, sobre todo en el Ateneo (Entrevista personal del 29-10-2017). 
componer sus obras maestras por vivir en pensiones ruidosas y miserables o porque tienen que mantenerse con trabajos que los apartan de la creación. En ese relato, Eusebio García Luengo -el bohemio autor del que el TEU representará El celoso por infiel- iría al servicio, donde se encontraría, escondido tras una tabla, un misterioso túnel hacia un país edénico en el que los escritores están provistos del tiempo, hogar y dinero que les permitiría crear sus obras magnas. Maravillado, Eusebio comunica a su vecino de mesa el extraordinario descubrimiento antes de volver al baño y desaparecer definitivamente por el túnel. Poco a poco, los escritores del Gijón repiten la operación, contándose el secreto unos a otros al oído y yéndose, uno a uno, hacia el baño, para ser recibidos con todos los honores en el paraíso de los escritores, donde viven con todo lujo y sosiego, y en consecuencia, nadie escribe ya nada ${ }^{5}$ (Ley, 1981: 20).

Un relato que explica en cierta medida la escasa producción publicada por el propio Ayesta, quien, terminada la Guerra Civil y con una clara vocación literaria, fue estudiante de Filosofía y Letras, pero, al morir su padre en 1942, optó por simultanear estos estudios con unos más prácticos de Derecho, que después lo llevaron a preparar oposiciones para ser diplomático con Fernando Morán y Tierno Galván. Como diplomático, y por tanto sin una acuciante necesidad económica, él mismo reconoce que eso le permite no tener que publicar-como escribe a Gimferrer (Ayesta, 2003: 14)-, romper con frecuencia lo escrito o dejar olvidados los textos inéditos e incluso los publicados que no siempre recopiló. ${ }^{6}$ Según todos los testimonios, Ayesta era hombre de conversación efervescente y en los primeros años del TEU, un ingenioso estudiante en la Facultad de Filosofía y Letras de la Complutense con grandes dotes literarias. Como escribirá su amigo Charles David Ley, «Daba la sensación de una fuerza natural, lleno de magnífico sarcasmo cuando hablaba y cuando escribía. Discutía de todo, criticaba todo» (1981: 53). Sin embargo, no creó «lo que su genio innegable prometía» (1981: 19).

A pesar de ello, Ayesta será inolvidable por su personalidad y su imperecedera Helena o el mar de verano. Para Medardo Fraile, Ayesta «es el recordado siempre por un solo libro de noventa páginas», el diplomático que «animaba la acosada vida literaria madrileña con ingenio de primera clase». Medardo Fraile, como otros contemporáneos, destaca de Ayesta sus frases, su originalidad y el

5. Lo cuenta Charles David Ley añadiendo: «Así es el cuento de Ayesta, que nunca se ha escrito, según creo, y aquí se ha puesto en letra de molde -salvo error- por primera vez» (La costanilla de los diablos. Memorias literarias 1943-1952, Madrid, José Esteban, editor, 1981, p. 20). Ley lo describe especialmente interesado en los temas religiosos (1981: 53).

6. He de agradecerle la información a su amable hija Mónica Ayesta, en la entrevista telefónica realizada el 25-10-2017.

Anales, 29-30 (2018), pp. 133-160 
talento de sus charlas y los cuentos rebeldes que leía y nunca se publicaban, y sobre todo, su interés como espectador y autor por el teatro, en el que, de haber sido otras las circunstancias, habría anticipado éxitos extranjeros. ${ }^{7} \mathrm{~A}$ pesar de las escasas obras teatrales suyas representadas, esa era su vocación literaria más decidida, como lo atestiguan las varias obras teatrales inéditas que aún se conservan. Sin embargo, son pocas las obras teatrales que nos han llegado, en parte a causa de esa vida de diplomático, pero también, según me ha confesado recientemente su viuda, Hélène Scarbonchi, ${ }^{8}$ por las constantes desilusiones que le ocasionó la censura, prohibiendo varias de ellas.

Convertido ya en diplomático -su primer destino en Bogotá fue en septiembre de 1949-, sus apariciones intermitentes por las tertulias y sus también intermitentes colaboraciones en prensa a causa de los más exóticos destinos (Colombia, Santo Domingo, Egipto, Sudán, Líbano, Austria, Francia, Holanda y Yugoslavia) fraguaron la aureola mítica que acompañaba al entonces conocido autor de Helena o el mar de verano (1952). A finales de los sesenta perfilará aún más esta aureola mítica su crítica periodística en línea aperturista. El periodista Parra Galindo lo recordaba en la redacción de SP como un caballero acompañado de un caniche y una elegante novia francesa, llevando un ejemplar de Le Monde bajo el brazo, con porte diplomático. Como también vemos en su obra literaria, como crítico político su humorismo nunca llegaba a la descalificación personal y era siempre ingenioso (Parra, 2012). Entre 1968 y 1969 publicará más de cuarenta artículos en la línea aperturista del Régimen para

7. Añade Medardo Fraile: «He oído hablar de una obra suya leída que, sobre un escenario y en circunstancias normales, se habría anticipado a un éxito londinense de muchos años más tarde: Loot, de Joe Orton», prólogo de Medardo Fraile a Tarde y crepúsculo (1993: 5). Se está refiriendo a la obra luego prohibida de 1953 Entierro de caridad, una entretenida Farsa metapolítica-subtítulo con que aparece en su manuscrito-, de la que he constatado que se hizo una lectura pública para «La Tertulia Literaria Hispanoamericana», probablemente sólo del primer acto, puesto que en los primeros años de la tertulia se publicaron cuatro números de la revista La Tertulia que, a juicio de su artífice Rafael Montesinos, son «hoy inencontrables y que representaban «fielmente los dos primeros cursos» (Montesinos, 1992: s.p). No sin dificultades, he podido encontrar el número 3 de 1953 en que efectivamente se publicó el primer acto de la obra de Ayesta bajo el título «Entierro de caridad o El triunfo de la equidad». Además, en el archivo de Rafael Montesinos se conserva una foto de Ayesta con él y Fernández Spencer que debe de ser de aquel encuentro u otro de fechas semejantes, pues además, el escritor ya diplomático en Colombia intervino en la concesión de varias becas a escritores de aquel país para que continuasen estudios en Madrid y se instalasen en el Colegio Mayor Guadalupe.

8. He de agradecerle también a Hélène Scarbonchi sus amabilísimas líneas a propósito de mi interés por la obra dramática de Ayesta. También ella subraya la singularidad de Ayesta, «una persona maravillosa, completamente aparte [que] ha dejado huella en todos los que han tenido la suerte de conocerle o simplemente de encontrarse con él» (correo personal del 21-11-2017).

Anales, 29-30 (2018), pp. 133-160 
la primera página de SP, el diario que rechazaba cualquier sumisión a grupos o partidos, y con los que se hizo famoso por firmar con el número de su carné de identidad. A pesar de la estrategia de la firma, fue desvelado el nombre del atrevido autor, hasta el grado de que será reconocido en la tradicional lista de los premios a los más «Populares» del año del diario Pueblo -junto a Massiel o Raphael-, en la categoría de Periodismo Político. ${ }^{9}$ El «premio» del gobierno al funcionario polémico, en cambio, será encargarle abrir embajada en Sudán, mandándolo a la lejana Jartum. Allí continuará escribiendo teatro bajo la mosquitera (Pau, 2001: 106), y allí también un comando terrorista secuestra a varios embajadores y mata a los de Estados Unidos y Bélgica. El exitoso rehén mediador será Julián Ayesta, que consigue la liberación del resto de diplomáticos, y a su vuelta a España es reconocido con honores y enviado, ahora ya, a mejores destinos. Pero la profesión diplomática sólo le permitió escribir con dificultades e intermitentemente. Como declaró una vez jubilado, la literatura y la diplomacia eran tareas incompatibles: «Un diplomático escritor es algo contra natura $»^{10}$ (Alonso, 2013: 18-19).

Juan Perucho le reconocerá inspirador de su propia obra, pero por encima de su obra publicada, también él insiste en la genialidad de su personalidad: «Ayesta es uno de esos hombres cuyo impacto en quienes le conocían rebasaba su obra escrita -o al menos publicada-, era una incitación al diálogo y a la inquietud intelectual» (Perucho, 2002: 25). En sus recuerdos del café Gijón, Francisco Umbral lo destacaba entre los cuentistas que lo frecuentaban -junto a Aldecoa, García Pavón o Pilares-, marcado por la intermitencia de los destinos diplomáticos que lo hacían aparecer y desaparecer de las tertulias, llevando una existencia poco compatible con la naturaleza estática de las «horasculo» de todo escritor:

Julián Ayesta, diplomático y escritor, tenía en el café un vago prestigio mítico por su ausencia y por su lejano libro Helena o el mar del verano [...] una obra lograda de lirismo, circunstancia y concentración ambiental. Más tarde, Julián Ayesta empezaría a hacer periodismo, venido ya a Madrid, con cierta audacia política que le llevó a tener disgustos como periodista y como diplomático. Me parece que volvió a desaparecer, pues éste era el destino errabundo de muchas estrellas del Gijón, y concretamente de los diplomáticos, que cuando además

9. Por sus artículos en SP y compartiéndolo con dos periodistas políticos. «Los populares de 1968 según el diario Pueblo», La Vanguardia Española, 15-12-1968 y ABC, 17-12-1968. Los testimonios de quienes lo conocieron reflejan un carácter crítico, si bien no tan rupturista como lo supone en su interesante ensayo Jordi Gracia (2004: 380) basándose, entre otras cosas, en una cita descontextualizada que toma de Pau (2001: 47).

10. «Cuando escribes estás un poco en trance, y ese trance dura horas, o todo el día, y eso es fatal para la diplomacia. Hombre, si se escribe historia o un poema de vez en cuando...». 
son escritores, pasan por la literatura como lunas intermitentes y cosmopolitas. La literatura suele ser una cosa estática, aunque haya escritores muy viajeros, y el estatismo del Gijón veía pasar con curiosidad, ironía y cordialidad a los grandes y pequeños viajantes de la literatura (1977: 243).

Sobre esta entonces famosísima novela sí se ha detenido la crítica, pero con las mismas dificultades que antes apuntábamos para encasillarlo de algún modo. Escrita en la posguerra y en pleno triunfo de un realismo social que, salvo en los grandes autores, se atascaba con frecuencia en una angustiosa autorreferencialidad grisácea sobre fondo negro, la novela de Ayesta contrasta por su retrato delicado, sensorial e impresionista que evoca el proceso de enamoramiento del protagonista desde la infancia, rompiendo en sus recuerdos la linealidad temporal en que el sentido de la realidad y del misterio se conjugan en una narración lírica. Recién publicada, causó el entusiasmo crítico de muchos como Fernández Almagro por su alcance lírico en conjugación con una exploración psicológica en que permanece «la vibración y temperatura de lo actual», así como los ecos del monólogo discontinuo de Joyce. Sin embargo, los matices y delicadeza de la materia novelada le dan un timbre «personalísimo» (1952: 8). Traducida a numerosos idiomas y constantemente reeditada (la última reimpresión de Acantilado es de mayo de 2017), es «novela de culto» de la que se ha dicho recientemente que es «uno de los diez libros más importantes de la narrativa española del siglo XX».

La mejor descripción es la que su autor, ya jubilado, dio de ella: «Había una chica, Elena Valdés-Hevia, que la recuerdo de unos años más acá. Pero en realidad creo que Helena fue un conjunto de vivencias de la época de los grandes amores. Los grandes amores duran hasta los catorce o los quince años... Son muy precoces, los amores que te llenan». Un libro marcado por el amor también a su tierra y a la propia infancia perdida: «Al término de la Guerra Civil quise reanudar la adolescencia que aquella había cortado, y, claro, fue imposible. Entonces ordené los recuerdos y me puse a escribir» (Alonso, 2013; 18).

De hecho, esta magnífica y particular «novela» de menos de cien páginas, es en realidad la reunión de varios cuentos publicados anteriormente en distintas publicaciones periódicas con unos mismos protagonistas y escenarios. El paisaje de su infancia, su casa de Somió, el estío, que en otros textos describirá con el «viento y cables desmelenados» que «robleaban entre crujidos» con sus «luminarias», son los mismos «paisajes azules eléctricos» de Helena (Ayesta, 2003: 68, 70). El primer «capítulo», por ejemplo, es el relato «Almuerzo en el jardín» que Ayesta publicó en el suplemento dirigido por José García Nieto de la revista Acanto (e ideada por Entrambasaguas; ambos intelectuales fueron 
determinantes en la biografía literaria del autor). Como aquí ya se ve, uno de los rasgos característicos de la obra literaria de Ayesta será precisamente la brevedad y uno de los rasgos de su personalidad el desinterés y descuido de su propia obra: olvidaba, rompía mucho, abandonaba textos en sus constantes viajes... y si no hubiera sido por el empeño de su primera mujer, nunca habría llegado a unir los capítulos que componen Helena o el mar del verano. ${ }^{11}$

\section{Primeras publicaciones como alférez provisional y estudiante universitario}

Terminada la Guerra Civil, Ayesta había iniciado sus estudios de Filosofía y Letras en la Universidad Central de Madrid. Escritor siempre «poético»-como autor dramático defiende la poeticidad de la situación, pero no del lenguaje-, la primera publicación de Ayesta serán unos poemas incluidos en la edición que realizó el profesor Entrambasaguas de la Antología del Alba (1940-1942). En ella publicará cuatro poesías junto a otros compañeros de Facultad y nuevos poetas como Alfonso Candau, José Luis Cano, Francisco García Pavón, Rafael Morales, Manuel Arroyo, Rafael Benítez Claros, Pablo Cabañas y Jesús Revuelta. Esos únicos poemas de los que tenemos noticia son: «Oda al día siguiente», «Noche con huracán del sur», «Tarde quieta de estío» y «Viento norte en noviembre». Todos ellos vuelven a remitirnos a la deliciosa escenografía y estilo de Helena. Clásico e intimista, su estilo, como el del resto de colaboradores, nada tiene que ver con el supuesto estilo falangista. Tomemos como muestra «Tarde quieta de estío»:

Las colinas se hunden en la calma morada
y los foros lejanos pastorean ensueños.
En las casas vacías incendiadas ventanas
en heliógrafo inmóvil para voces sin dueño.
Una angustia imprecisa ha quedado dormida
a la orilla de un mar aquietado y sangriento
mientras barcos de oro con muchachas y músicas
zarpan desde algún sitio a las islas del viento.

La temática de la obra de Ayesta, como la de otros falangistas, está totalmente ajena al «planto por la decadencia de la patria; la preocupación por un estilo viril y poético de la vida; los ataques al capitalismo judío e internacional; el militante antiseparatismo; la exaltación guerrera y militarista y la preocupación mundial». Nada que ver con esa retórica «de la intemperie, lo exacto, máximo o inexorable, la milicia y lo imperial, la impasibilidad, la claridad y el heroísmo frente a lo bárbaro, lo turbio, lo chillón y lo estéril» (Mainer, 1971: 31). Ana

11. Testimonio personal de su hija Mónica Ayesta (26-10-2017).

Anales, 29-30 (2018), pp. 133-160 
Casas precisa justamente la importancia de la inclusión de elementos apoéticos y antirretóricos -aquí, el heliógrafo- con una estética rehumanizadora propia de la Falange, desechando en cambio la fascista (Casas, 2007: 66-67). Para entender la obra de Ayesta e incluso los asuntos que tratará en sus obras teatrales, es fundamental recordar el emocionado patriotismo del joseantoniano catedrático de la Universidad Central, Joaquín Entrambasaguas, y el esperanzado papel que atribuye a esta generación de jóvenes universitarios entre los que se encuentra nuestro autor. Ayesta pertenece a un alba generacional de poetas a la que atribuye un papel simbólico en la Facultad de Filosofía y Letras de la Universidad Central. En el pasado, el ambiente de la Facultad era «sórdido, friolento, de egoísmos políticos crecientes o indiferencia oficinesca resignada». Era milagroso que el estudiante que llegase a ella como poeta «no quedara curado de versos para siempre entre tanta lengua muerta y tanta asignatura sin vida». Todo ello reproduce una situación y tipos que captará Ayesta en El tímido Serafin:

La Facultad, la Universidad, nos quería así, en sus pasillos lúgubres y en sus aulas polvorientas; en su vida hostil, sin más bocanada de alma y paisaje que el descuidado jardín de aquel caserón desmantelado donde, pese a todo, tenemos aún cosidas nuestras almas...

Aquella generación de estudiantes -la de José Antonio, claro es- se formó así y a trastazo limpio, en esa sequedad de Universidad sin Poesía (Entrambasaguas, 1943:10).

Esta nueva generación de Ayesta halló en la guerra «la dureza que templa las almas» y en la Universidad «el remanso sereno de la poesía». El catedrático insiste en que esta es la primera generación de estudiantes de Filosofía y Letras de la Central que, además de trabajar mejor que nunca, «forman una milicia y crean poesía; que son soldados y poetas como Garcilaso, con espada en la guerra y pluma en la paz» (1943: 11).

De hecho, muchas de las afirmaciones del catedrático en el prólogo de la Antología del Alba (1940-1942) son las mismas que leemos en las publicaciones periódicas del SEU, en las que también colaboraba Ayesta, como Juventud y $\mathrm{Haz}$; las mismas ideas que vemos en otras publicaciones universitarias como Alferez o Cisneros (en esta última publicó Ayesta El tímido Serafín que estrenó el TEU de Madrid). En todas estas composiciones poéticas, vemos el ímpetu de quienes comienzan una etapa histórica de reconstrucción, empezando por la renovación universitaria de los que fueron pasillos lúgubres y aulas polvorientas del pasado. La antología poética incluye composiciones de trece poetas 
nacidos casi todos entre 1919 y $1923,{ }^{12}$ rondan los veinticinco años y la mayoría no han publicado nada antes -con excepciones como Cano, Morales o Viejo Otero..$^{13}$ Significativamente, concluye la antología el poema de Viejo Otero «Dolor y ausencia de la ciudad universitaria», que refleja esa nueva ansia de vivir de los primeros estudiantes tras la contienda.

Gráficamente, el colofón del libro explicita ese ímpetu generacional nuevo que hace suyo el papel de soldados poetas: «Renacer fuerte y dulce de Garcilaso», impreso, LAUS DEO, «Para mayor gloria de la Universidad». Destaco este colofón porque sintetiza muy claramente la actitud generacional de estos autores: asumen que son, por la gracia de Dios, poetas, en un tiempo pasado soldados y ahora universitarios. El propio Ayesta será poco después colaborador de la revista Garcilaso. Juventud Creadora, fundada por García Nieto, en que se asume ese clasicismo enriquecido por la poesía moderna; una poesía intimista, humana, ligada más a una experiencia anímica o sentimental que a una ocasión histórica o externa -nada combativa, grandilocuente ni política. Eso mismo es Helena o el mar de verano, que para más señas se inicia con dos citas: la garcilasiana, «Por ti la verde hierba, el fresco viento,/ el blanco lirio y colorada rosa/ y dulce primavera deseaba», y la de un libro tan importante entonces como Sombra del paraíso, de Aleixandre: «Pero lejos están los remotos días/ en que el amor se confundía con la pujanza de la naturaleza radiante/ y en que un mediodía feliz y poderoso/ henchía un pecho, con un mundo a sus plantas».

En el mismo número de Cisneros en que Ayesta publica su obra teatral El tímido Serafin, Castro Cubells dedica un artículo a la «Facultad de Filosofía y Letras» de la Universidad Central. Recuerda el comienzo del curso 1939-1940, tras el forzoso silencio de la guerra, y cómo resurgió entonces la esperanza, pero en medio de la estrechez máxima, viviendo universitariamente gracias a la generosidad de otras facultades, dado que la guerra había acabado con el

12. A excepción de J. Revuelta de 1918, J. A. Sopranís nacido en 1917 y del mayor de todos ellos, José Luis Cano de 1912.

13. La antología incluye las composiciones de Manuel Arroyo, Julián Ayesta, Rafael Benítez Claros, Pablo Cabañas, Alfonso Candau, José Luis Cano, Jaime Delgado, Francisco García Pavón, Rafael Morales, Salvador Pérez Valiente, Jesús Revuelta, José Antonio Sopranis y Eliseo Viejo Otero. Antecediendo a las composiciones poéticas, se dedican unas líneas a cada autor. Varios de ellos coinciden publicando en Haz, donde Ayesta publicará también cuentos. De Julián Ayesta leemos «Nació en Gijón el 14 de noviembre de 1919. No ha publicado nunca poesía. También cultiva la prosa y el teatro. En la actualidad trabaja en una novela que titula "Serafín Adelfa" ». Como tantos otros escritos de Ayesta, esta novela nunca vio la luz, si bien, por fecha y asunto apuntado en el título podría tratarse del mismo argumento de la obra teatral que publicará ese mismo año El tímido Serafín. 
primer edificio de la Ciudad Universitaria. Es justamente en octubre de 1943 -el mismo curso en que el estudiante Ayesta publica su obra teatral- cuando se inaugura oficialmente la Ciudad Universitaria: «Para todos los estudiantes, aquel día tuvo un gran significado de Fe y de Esperanza, pero especialmente para los pertenecientes a la Facultad de Filosofía y Letras, que volvían a tener casa propia, espacio amplio y nuevos horizontes» (Castro, 1943: s.p.).

Ese «alba» es la que esta generación de universitarios y escritores debe construir, el mismo espíritu renovador que emprendería el TEU. De la vieja Universidad de lenguas muertas y «asignaturas sin vida» surge ahora esta generación que, a decir de Entrambasaguas, durante la guerra protegió y conservó íntegra la sensibilidad para derramarla en la poesía pura. Esta generación encarna el ejercicio de las letras y el de las armas, convirtiendo en modelo predecesor a Garcilaso. Así, «surge una generación de estudiantes que, además de trabajar, mejor que nunca, forman una milicia y crean poesía; que son soldados y poetas como Garcilaso, con espada en la guerra y pluma en la paz» (Entrambasaguas, 1943: 11).

Las aportaciones literarias de algunos autores como Julián Ayesta a las publicaciones como Haz, Juventud o Alferez manifiestan semejanzas con la de otros autores de las mismas publicaciones, y por estilo y temas explican el carácter inconformista de muchos que después evolucionan hacia la socialdemocracia.

Como muestra de la relación entre el TEU y la prensa del SEU, mencionábamos antes que en Haz podían leerse artículos de los pocos autores noveles a los que la agrupación de Modesto Higueras representó. Antes de estrenar su primera obra con el TEU, Ayesta había publicado en él un cuento interesante para entender el trasfondo ideológico de estos jóvenes: «La República. Memorias de un joven burgués» (Haz. Revista Nacional del SEU, $\mathrm{n}^{\circ}$ 2, marzo de 1943). Nótese que, sin crítica alguna, lo reprochable para estos falangistas no es lo ideológico, sino la actitud acomodaticia que se identifica con ser «burgués». Su relato del momento del advenimiento de la República es amable, ajeno por completo a cualquier rastro de soberbia vencedora. Lo más crítico que se puede advertir es una leve ironía al describir la grandilocuencia y el tono mayestático de sus partidarios que se consideraban ejemplo para toda Europa, en párrafos como este:

-Señores, Europa entera nos está mirando...

Desde las bocas de riego y los sótanos ignorados, desde el tejado rojo y parpadeante que miraba al oeste y las gafas gigantescas y azules de la muestra de los ópticos, tal vez desde los escaparates oscuros de las mercerías al por menor, toda Europa miraba la proclamación de la República. Su monóculo y su guiño taladraban la perspicacia de las autoridades legítimamente constituidas 
que prohibían los borrachos con razonamientos fríos y metálicos como pescadillas recién sacadas (Ayesta, 1943: 14).

Sólo el subtítulo anuncia lo más criticable de todo aquello y que reaparecerá en sus obras teatrales para el TEU: su irónica mirada hacia la burguesía acomodaticia. El tío Alfredo del relato -al que, por lo demás, retrata con entrañable cariño-, es silencioso para los demás, pero audaz republicano católico-anticlerical en la casa de su conservadora hermana, quien, por otro lado, también es humorísticamente disminuida a una «voz desmayada y siflomística». En definitiva, Ayesta está retratando la complejidad ideológica de la Guerra Civil tal y como él mismo la vivió, como hijo de republicano de derechas. ${ }^{14}$

\section{Aportaciones de Ayesta al TEU}

Así, el joven alférez provisional estudiante de Filosofía y Letras, con tan sólo cuatro poemas y un cuento publicados, pero con una personalidad desbordante, se convertirá en el primer autor novel seleccionado, sin embargo, para ser representado por el TEU.

\section{Simplemente así}

Se ha prestado muy poca atención a esta notable y breve obra teatral de Julián Ayesta. Antonio Pau, quien no sólo ha escrito una biografía sobre Ayesta, sino que además lo conoció, afirma que se estrenó en el Teatro Español, representada por los actores del TEU y dirigida por Modesto Higueras (Ayesta, 2001: 83 y como obra estrenada, Ayesta, 2003: 14). ${ }^{15}$ Aunque, como sucede con otros montajes del TEU, no tenemos más referencias, reúne todos los requisitos para creerlo.

Según me ha confirmado su hija, muerto el padre de Ayesta en 1942, su madre tuvo que regresar a Gijón, mientras Ayesta permanecía en Madrid como estudiante de Filosofía y Letras que, además, iniciaba estudios de Derecho y vivía en el Colegio Mayor Jiménez de Cisneros, «un par de cursos al menos». ${ }^{16}$

14. El escritor era hijo de Julián Ayesta Manchola, abogado de prestigio y periodista, fundador de El Comercio de Gijón, y fundador también del partido Derecha Liberal Republicana, siendo diputado de la conjunción republicano socialista de 1931 (Cuesta, 2006).

15. Sin embargo, no hemos encontrado más referencia a su representación y, en cambio, El tímido Serafín es recibida por Villacorta (Arriba, 8-3-1943) como primer estreno de Ayesta. Quizás pudo tratarse de una representación leída o una representación en el Colegio Mayor, posiblemente organizada por el SEU.

16. Entrevista telefónica realizada personalmente a Mónica Ayesta el 26 de octubre de 2017. A excepción de las entrevistas concedidas en vida por Ayesta, en que hace alguna alusión a su vida, la única biografía sobre él es la realizada por A. Pau como introducción a los 
El Cisneros fue heredero de la Residencia de Estudiantes, hospital y hasta cuartel de milicianos durante la guerra, y será el primer Colegio Mayor que reinstaure el Ministerio de Educación Nacional en vinculación a la Universidad Central (Ibáñez Martín, 1943: 5-6). Con estos Colegios Mayores se «aspira a que en ellos los escolares reciban, a más del complemento cultural necesario a sus estudios, la imprescindible educación religiosa, política, social, estética, deportiva y la del trabajo» (Sánchez-Bella, 1943: 60). También estudiante de Filosofía y Letras en la Central y compañero del Cisneros -como Ayesta-, el futuro Ministro de Información y Turismo (1969-1973), Alfredo SánchezBella destaca la fecunda vida cultural del Colegio Mayor en que se alojan en aquel momento ciento cincuenta estudiantes, bajo la dirección de Pedro Laín Entralgo. Por el Colegio pasarán escritores y artistas, se celebran cursillos, sesiones periódicas de cine, conciertos dos veces al mes, además de tener una intensa vida deportiva, como lo demuestra la celebración estudiantil de las Olimpiadas deportivas (tenis, hockey, fútbol...) La crónica de actividades incluye la «asistencia a la puesta en escena de nuestras más celebradas obras clásicas», entre las que podría haberse representado la pieza de Ayesta, como era costumbre hacer en las representaciones del TEU.

Ayesta vive en primera línea el despertar universitario y la vinculación de esta juventud creadora en el impulso entusiasta a la cultura. Las numerosas actividades deportivas y culturales del Colegio Mayor serán recogidas en la revista Cisneros que empieza a publicarse en enero de 1943. Simplemente así se publica en el primer número de la revista universitaria del colegio mayor de la futura Complutense. Por el tema que desarrolla, veo muy factible que la representación de la obra se realizara el 9 de febrero de aquel año, conmemorando «El día del Estudiante Caído», que toma la fecha del asesinato, nueve años antes, del estudiante de Medicina y cofundador del SEU Matías Montero, tiroteado mientras vendía el periódico de la Falange (FE). En dicha conmemoración, el SEU participó en varios actos que homenajeaban a todos aquellos estudiantes falangistas que habían sido asesinados por su ideología ${ }^{17} \mathrm{y}$ quizás uno de los actos conmemorativos fuese la representación de esta pieza.

Simplemente así es una "comedia trágica, en cuatro actos». Como también veíamos en «La República», Ayesta atestigua grandes acontecimientos

Cuentos. Sin embargo, salvo la mención a sus estudios, poco más se sabe de los años universitarios en que escribió las obras teatrales para el TEU y sus cuentos.

17. «Hoy, con el recuerdo vivo de Matías Montero, el Frente de Juventudes conmemora solemnemente en toda España el Día del Estudiante Caído», ABC, 9-2-1943. El artículo equipara el idealismo de aquellos jóvenes con los divisionarios actuales, como también hace Ayesta en esta obra. 
históricos nacionales sin exaltación alguna, criticando amablemente la pasividad burguesa ante el drama, incluso cuando, convertidos en víctimas, siguen sin salir de su atonía. La rebeldía de Ayesta lo es contra lo establecido e ineficaz, contra la generación anterior incapaz de cambiar las cosas antes de la guerra y contra la actual supervivencia de esa falta de movilización, tan murmurante como inactiva, que el escritor quiere desenmascarar en la obra para que no se imponga en el futuro. Tras el texto, Ayesta añade unas líneas reflexivas:

Mansa y desoladora historia que no hay por qué callar. Porque el que calla se hace cómplice de lo callado y si aquello es vergonzoso, desvergonzado será el cómplice. Porque nosotros no queremos tales alianzas hablamos así. Y el que crea que escandalizamos, ¿ipiensa acaso que es escándalo decir que los pájaros vuelan o que nadan los peces? Si todos jugamos en esta comedia -y los que se escandalicen mucho más-, ¿por qué asustarse ante el espejo?

Simplemente así es el espejo que Ayesta pone ante la sociedad de posguerra con el deseo de evitar la repetición de ese modo de actuar que engendró la Guerra Civil:

Más vivos que en retratos más actuales que nosotros mismos, los muertos nos juzgan desde su morada y nos ven impasibles, como si su sacrificio hubiera sido un episodio sin importancia. Los muertos nos contemplan por sí mismos; no creen los artículos de encargo ni los discursos de ocasión (Ayesta, 1943: p. 94).

Ya en este temprano texto, el escritor busca lo poético en la situación y ambiente, pero no en el lenguaje, que busca la expresión natural. Ese «Simplemente así» del título advierte de cómo la inercia arrastra a la tragedia, y eso es lo que sucedió en el pasado inmediato y lo que sucederá en un futuro si no se remedia. El autor escoge cuatro fechas de la Historia española reciente para los cuatro cuadros de la pieza: 1933, 1937, 1941 y 1942. En los cuatro cuadros recrea poéticamente esa inercia de quienes constantemente lamentarán prosaicamente el precio del trigo, la escasez de comida y la dificultad material de sobrevivir. Para teatralizar la pasividad burguesa, la ambientación ha de buscar la monotonía en la repetición en todos los cuadros del mismo decorado, los mismos personajes sentados en los mismos sitios y hasta el mismo sonido de piano, que ha de insistir «en su taladrante y pesadísima lección» de solfeo. Durante los cuatro cuadros y momentos históricos, los mismos personajes permanecen en una sala confortable de clase media. Sobre el gran sofá del fondo se ve un «cromo» del Corazón de Jesús -en señal de lo superficial y convencional de su religiosidad. Todo ello se repetirá en los cuatro cuadros, destacando así la única novedad que supondrá la aparición sucesiva en cada uno de ellos de un nuevo 
retrato enmarcado en negro que se van sumando, mostrando al espectador las víctimas de esa pasividad.

En el cuadro inicial de 1933 los personajes comentan la falta de libertad religiosa que viven bajo el gobierno de Azaña y la escasez de alimentos, pero lo único que hacen es lamentarse e ironizar. Hablan también de los primeros estudiantes falangistas asesinados por su ideología, pero los llaman «gente del hampa», en referencia precisamente a las críticas que se despertaron ante el asesinato del falangista de quince años Jesús Hernández, de cuyos asesinos José Antonio Primo de Rivera había sido el acusador particular ( $A B C, 11-4$ 1934). Cabe destacar que Ayesta mismo se había afiliado a la Falange cuando sólo tenía quince años, al poco de la Revolución de Asturias. Por eso, los personajes aburguesados manifiestan su desdén hacia los chicos que juegan «a lo Mussolini», con una ironía que parafrasea el conocido discurso de Primo de Rivera en el Parlamento contra los «alifafes, accidentes y galanuras» del fascismo en el mismo año de afiliación del autor a la misma. ${ }^{18}$ El asunto de la obra refleja, en definitiva, el contenido de varios de los artículos que José Antonio Primo de Rivera había descrito en el mismo periódico del SEU del que ahora Ayesta es colaborador, particularmente, «Sentido heroico de la milicia» y «Mientras España duerme la siesta» (Haz, 1935).

En los siguientes cuadros, se repiten situación y desenlace, aunando la valentía de los jóvenes anteriores a la Guerra Civil, que dieron su vida por enfrentarse al comunismo, a los de la guerra y posguerra, en referencia a la División Azul. En 1942, ya muertos todos los hijos de esos burgueses acomodados en sus sillones, aún se lamenta superficialmente uno de ellos de que no «hay criterio de gobierno ni hay nada». Simplemente así, se escribe la Historia: con la repetición de los errores que ocasionan las muertes de los que quieren cambiar las cosas.

Simplemente así conmemora a los estudiantes caídos con el indudable acierto de ser una obra política que no se venga ni hace crítica del bando vencido en la contienda, del que nada se nos dice en toda la obra. Y téngase en cuenta, además, que sortea ingeniosamente la salida fácil de hablar de verdugos socialistas, comunistas o anarquistas. Sin acritud alguna, los estudiantes asesinados son víctimas de la impasibilidad española ante la tragedia, del egoísmo e inoperancia de los espectadores de los hechos que, aun viviendo las estrecheces

18. Ayesta fue jefe de centuria falangista, seuísta activo y colaborador de la misma publicación. Por eso es un error identificar su pensamiento con el de quienes critica. Señala Juan Lázaro que en esta obra se critican a Azaña, a Mussolini y al gobierno de 1942 (Lázaro, 2013: 2). Sin embargo, el comentario es irónico y no crítico contra Primo de Rivera, sino contra quienes desconocen su alejamiento del fascismo de 1934. 
del conflicto nacional, no hacen nada por cambiar la situación. Es una lección amable que avisa a los espectadores de que nosotros mismos en la actualidad podemos ser como los personajes de la pieza.

\section{El tímido Serafin}

De esta pieza, tanto la familia del autor como el Centro de Documentación Teatral conservan el programa de mano de la representación realizada por el TEU de Madrid y dirigida por Modesto Higueras en El Español el 8-6-1943, aunque fue también representada por el TEU de Zaragoza (Bajo Martínez, 2015: 66). ${ }^{19}$ En su estreno madrileño, tras la breve pieza de Ayesta, se representaron El cartero del rey de Rabindranath Tagore y Los borrachos de Quiñones de Benavente $e^{20}$, y a pesar de lo bien acompañada que iba la pieza, El tímido Serafín atrajo la atención de la crítica y público, que la aplaudió mucho. Arriba, $A B C$, $Y a$, Madrid o Informaciones recogerán sus impresiones favorables sobre la obra al día siguiente del estreno. Todas las críticas coinciden en alabar las «excelentes dotes de comediógrafo», el «fino humorismo» con «trazos hilarantes» (Arriba, 9-6-1943), la «sátira llena de gracia y fino ingenio, en la que su autor maneja las figuras con habilidad teatral y subraya con acierto la lucha interior de Serafín y sus indecisiones» (Marqueríe, Informaciones, 9-6-1943) y el «talento para la invención, fantasía y gracia, soltura y desembarazo en los diálogos», de «fresca y jugosa gracia» (C., Madrid, 9-6-1943). Ayesta -nos dice esta última crónica-, «se nos revela como una promesa de autor muy estimable, deseoso de encontrar caminos limpios y nuevos al teatro dialéctico».

El universitario Ayesta publicará esta obra en la revista de su Colegio Mayor, el Cisneros. Como la anterior pieza, se trata de una amable crítica a la falta de voluntad y a la inacción, y otra vez, se trata de una crítica generacional, sin banderías políticas, de quienes, siendo jóvenes, han estado cerca de la muerte en la guerra y ahora se acogen al calor de las letras -escribe, emulando la idea garcilasiana de Entrambasaguas. La obra:

19. No se nos indica fecha ni lugar de esta representación zaragozana.

20. El CDT la tiene mal fechada como estreno de 1952, si bien la prensa recoge su estreno en esta otra fecha. Ficha técnica: Dirección escénica: Modesto Higueras. Escenografía: Juan Ismael, realizado por H. Sancho Lobo. Intérpretes: José Luis Lopes, Cecilia Ferraz, Fermín Lapuente, Antonio Cabrera, Augusto Higueras, Ana María Saizar, Ana M. Mateos y Salomé Notario. Otro error al transcribir la ficha del CDT lleva a J. Lázaro (2012) a suponer varios cambios en la representación, como la supresión de los personajes de la sombra y del estudiante que aparecían en la versión publicada en la revista Cisneros, 1943. Sin embargo, en el programa de mano sí están dichos personajes. 
Es una bufonada escrita, entre otras cosas, para poner en ridículo a cierta gente que lo merece. Ataca al tipo de intelectual tímido, inhibido, que una generación templada tanto al filo de la muerte en guerra como al calor de las letras, no puede menos que rechazar. Que ese tipo existió y existe es indudable.

Aunque se teatraliza la imposibilidad amorosa del tímido, lo que es criticado humorísticamente es la incapacidad para la acción en general. Según dice el autor, el motivo de la pieza es ridiculizar el modelo de intelectual que asiste a la vida como un espectador evitando ser su actor -en definitiva, semejante a lo visto en Simplemente así. Ese modelo intelectual es el que Ayesta reconoce en una de las «bestias negras» del falangismo de la inmediata posguerra: Ortega y Gasset. Prologando la pieza escribe:

En la Conversación en el golf (El Espectador, IV), se lee esta charla entre unas muchachas y el prototipo del intelectual por excelencia: «-Yo no comprendo cómo puede usted vivir sin tomar el sol... -Es que no vivo (le respondo). -Pues ¿qué hace usted? -Asistir a la vida de los demás».

En realidad, el asunto literariamente debería remontarnos al «hombre superfluo» de Lermontov, que en España noveló y hasta dramatizó Galdós en Realidad (1892). De ahí, obras teatrales como la galdosiana Voluntad (1895), que toca tema después tan azoriniano y ganivetiano que se convierte en asunto central de la literatura noventaiochista. Serafín es un erudito incapaz de salir de la teorización para convertir en acto aquello sobre lo que tanta bibliografía maneja, exactamente igual que sucede con el personaje del drama galdosiano de 1895. Ahora bien, el antecedente de Ayesta es el Ortega que afirma:

Yo atestiguo que usted existe, que es usted ahora, prisionera de los rayos solares, casi un mito perfecto; que el cuello de leopardo en que culmina su abrigo es auténtico, hasta el punto que siento no haber traído el arco y las flechas, ya que ganas de cazar a nadie le faltan, señora, por muy mártir que sea...

Testigo soy, un testigo de la gran maravilla que es el mundo y los seres en el mundo. ¡Y no es misión despreciable, ninfa amiga! Si no existe alguien que atestigüe la existencia de las demás cosas, ésta sería como nula (Ortega, 2017: 523).

Ante la tentación de empujar con un palo la pelota de golf, el personaje orteguiano siente que le acarrearía castigos milenarios por ser indócil a su dharma, entendido como sublime empirismo de la moral. En realidad, el texto de Ortega destila el mismo humor ridiculizador de Ayesta, pero el joven escritor llevó aún más lejos que José Antonio su crítica al pensador en el artículo que le dedicó, otra vez, en Haz: «La política y el intelectual: Homenaje y reproche a Don José Ortega y Gasset». En él se observa la admiración del líder falangista hacia el catedrático de Metafísica, pero al que reprocha su última impasibilidad política. 
A Ortega y Gasset, José Antonio lo llama «maestro de la Juventud», pero le recrimina haber abrazado la causa republicana y que cuando ésta se desvió del ideal, lo que el intelectual hizo fue limitarse a contemplarla:

[...] hay que percatarse de que el paso de la ciencia a la política implica una tragedia: la de revisar constantemente sus propias conclusiones; la de conferir a sus conclusiones la condición de provisionales. El método filosófico arranca de la duda; mientras se opera en el campo de la especulación hay, no ya el derecho sino el deber de dudar y de enseñar a los otros a que duden metódicamente. Pero en política no; toda gran política se apoya en el alumbramiento de una gran fe (Primo de Rivera, 1935: 1).

En cualquier caso, la prensa seuística invita constantemente a esa idea de trabajo y sacrificio para el bien común. En otra de las publicaciones periódicas de universitarios falangistas en que Ayesta publicará -en Alférez-, leemos en las dos primeras páginas a José Luis Pinillos «cantarles las cuarenta» a los más jóvenes estudiantes que no han participado en la guerra que costó un millón de muertos y ahora están en la Universidad llenándose la boca de teorizaciones abstractas:

Para empezar diré a boca de jarro que España está harta, harta hasta la indigestión y las náuseas, de espectadores inteligentes, de teóricos hipercríticos y frívolos, que resuelven con una frase elegante los problemas más dramáticos, y que frente a la tarea de reconstrucción espiritual que a todos nos aguarda, su única reacción es la fácil y poco viril de señalar defectos (Pinillos, 1947: 1-2).

Está claro que el protagonista de la obra de Ayesta es un teórico universitario, un profesor de la Facultad en que estudia el escritor. El crítico A. M., de Informaciones al comentar entusiasmado la pieza, incluso aventura qué profesores están representados en Serafín: «las alusiones circunstanciales y de vida estudiantil -a don Ramón o a Entrambasaguas- con las que se salpimienta el diálogo tienen su espontáneo e innegable encanto» (A. M., 9-6-1943). Con nombre y apellido aparece el mismo tipo en su «estampa» para Garcilaso «Improntu para Masoliver», donde entrevera recuerdos del pasado inmediato, entre los que están las «Tristísimas tardes cómo Dámaso Alonso explicando sin fe Filología Románica sentado sobre la mesa, riéndose por lo bajo de la línea Spezzia-Rávena, que separaba la Romania Oriental de la Occidental, hasta que el Octavo Ejército cayó sobre el valle del Po e impidió con mucha protección aérea que las sordas intervocálicas $p, t, k$ sonorizaran en $b, d, g$ en toda la Italia del Norte, desde Trieste a los Alpes saboyanos [...]» (1944: s.p.).

Serafín lleva media vida sin decidirse a nada ni profesional ni personalmente. Exagerando hasta el extremo la asociación que Gerardo Diego hacía 
entre colores y músicas, ${ }^{21}$ Serafín ha dedicado su vida a poner música al zodiaco y a adscribir colores a los siglos, creyendo que vivía, pero sin vivir realmente. Exagerado y sin el ingenio del poeta, esta asociación sinestésica late en el ridículo protagonista de la pieza: hombre reducido al pensamiento sin acción, cuyas mayores aportaciones al conocimiento son haber puesto música al Zodiaco, siguiendo el mismo método de asociación, y haber dado colores a los siglos.

La literatura le ha servido para encerrar aquellas voces calientes de los enamorados en el marco perfecto de la frase «sin oírlas gritarle». Cuando una joven rubia entra en el escenario, se enamora perdidamente e imagina cómo podría retenerla. Pero incluso aunque ella busca excusas para quedarse más tiempo y volver a verlo, él no sale de su timidez y pierde toda oportunidad de entablar una relación con ella. La Sombra del propio Serafín, audaz y decidida, le va haciendo ver sus fallos, sus «otro día será, para qué seguir, hay pocas posibilidades», con que excusa su inacción. En una actuación de la obra que destaca -según Villacorta, el crítico de Arriba-, por su expresión y mímica, Serafín se propone actuar y, apasionado, nos describe su cómico plan para seducirla:

Yo me subiría en la Biblioteca a las librerías más altas para arrojar los libros al suelo. Bailaríamos saltando sobre las notas bibliográficas y las ediciones meritísimas; destrozaríamos a patadas las obras de Emilio Cotarelo y Mori y las de Gastón de Paris. Parapetados en barricadas de estudios y monografías sobre los orígenes de la lírica, nos bombardearíamos con proyectiles de rosas y cuando, cansados, nos quedásemos quietos, yo le diría los apacibles alejandrinos de Berceo:

«En nomme de Dios Padre que fizo toda cosa et Jesucristo, fijo de la Gloriosa...»

¡... O no! ¡Cantaría «La Parrala» entre los códices miniados! ¡«Ojos verdes» entre las cándidas figuras antiguas! ¡Lo alborotaría todo para acompasarlo con mi alegría, lo destrozaría todo para convencerla de mi poder, rompería con toda esta vida mía, llena de estudios críticos sobre el amor en Garcilaso, o de análisis bibliográficos sobre los madrigales en sabe Dios qué siglo para enamorarme yo, yo, yo! ¿Me entiendes? (Ayesta, 1943: 161).

21. Ayesta recordará en «Improntu» y en «Somió, entonces» (Pau, 2003: 68) cómo durante su infancia venía el sonriente Gerardo Diego. Allí, tras interpretar «Sor Monique» de Couperin, preguntaba a los concurrentes si Monique era rubia o morena, e intentaba que por el tono mayor o menor adivinaran el color del pelo. En su precioso «La lengua reformada», Ayesta recuerda a un viejo profesor que, en asociación semejante, explicaba que «pájaro» sólo es el que va volando, porque el que se mece en la rama es «pajáro»y si anda por el suelo es «pajaró» que, si ya ha sido alcanzado por un cazador, aumenta el peso de su acentuación aguda (1954). 
Todo ese conocimiento adocenado, esos pasillos lúgubres de la Facultad de Filosofía que nos describía Entrambasaguas en el prólogo de su contemporánea Antología del Alba aparecen cómicamente aquí. La obra de Ayesta es una comedia que invita a la acción y quiere despedirse de la Universidad adocenada y teórica para dar la bienvenida a la nueva Universidad. La prensa universitaria de esos momentos está llena de artículos sobre el renacer de la Universidad Central y el nuevo edificio de Filosofía y Letras ${ }^{22}$, y la prensa del SEU, llena de artículos sobre el hombre nuevo contrario al diletantismo y al egoísmo. ${ }^{23}$ «Ahora tienes la ocasión, aprovéchala»-dice la Sombra-, es el momento de emprender una nueva vida, una auténtica vida. La Sombra zarandea al hombre viejo, invitándolo a la acción, a que «astille las imágenes que no dan sino sed» de auténtica vida, a que se ría «de las descripciones sobre el amor y de la delicadeza de los madrigales en tercetos» (Ayesta, 1943: 164). Pero Serafín no es capaz de convertir en realidad lo imaginado, por eso, la obra es una «Comedia o tragedia, según para quién».

\section{La ciudad lejana}

El 30 de mayo de 1944 el TEU de Modesto Higueras estrena en El Español una versión del propio Higueras de la cervantina La cueva de Salamanca, acompañada en su representación de La ciudad lejana, escrita en colaboración de Alberto Crespo y Julián Ayesta. ${ }^{24}$ Según el programa de mano -conservado por la familia del escritor y el Centro de Documentación Teatral-, la realización y dirección es de Higueras; el vestuario, de J.L. López Vázquez y los decorados

22. Por ejemplo, C. Castro Cubells publica en el suplemento del número de Cisneros «La Facultad de Filosofía Letras», en el tono optimista de quienes estrenan edificio.

23. También en Cisneros, Carvajal firma «Tipología del estudiante de Filosofía y Letras» en que contrapone el tipo del estudiante de Derecho al del que considera opuesto estudiante de Filosofía y Letras (1943: 5-6). Véase también «Idea falangista del hombre» de Pedro Laín Entralgo, que inaugura las primeras páginas del primer número de Cisneros, en calidad de primer director del Colegio Mayor en que vivió Ayesta. El tema era considerado tan importante que con él abrió el número de Alférez J. L. Pinillos, con su artículo ilustrado y de varias páginas «Los confiados egoístas», donde reflexiona sobre ese tipo de estudiante universitario «fauna que abunda» llena de «frivolidad espiritual» (31-8-1947).

24. V. García Ruiz dice que se estrenó al alimón con el teatro Lope de Rueda y da como fecha el 26 de mayo de 1944 (2003: 88-89). De hecho, en la ficha del CDT se señala que la producción de la obra fue del TEU y del Teatro Lope de Rueda y se realizó el 26 de mayo de 1944, aunque la fecha correcta es la del programa de mano, cuatro días después, y no dice nada de que fuera en coproducción. La crítica de la obra publicada en Informaciones, firmada con las siglas C.E. (31-5-1944) es la única que hace referencia a que «el grupo teatral Lope de Rueda» trabajó muy bien en esta representación bajo las órdenes de Modesto Higueras. 
de J. G. Ubieta, realizados otra vez por Sancho Lobo. En los papeles principales actuaban una jovencísima Nati Mistral (Natividad Macho, que por entonces tenía ya algún premio, pese a tener sólo 16 años) y el gran actor Valeriano Andrés (por entonces con 22 años), interpretando a Ak, el protagonista.

Alberto Crespo tuvo una trayectoria ideológica semejante a la de Ayesta, a quien debió de conocer en Haz. Había sido director de la revista Cartagena Nueva, del diario Libertad de Valladolid y, después de la guerra, fue el director de la segunda época de la revista del SEU, Haz, en que también colaboró Ayesta y otros autores noveles del TEU. Además, fue divisionario y al año siguiente del estreno de La ciudad lejana escribió sobre su experiencia en las interesantes Memorias de un combatiente sentimental (1945), también publicadas por la editorial Haz.

Lamentablemente, la obra no fue publicada, no la conservan los familiares de los autores y las escasas referencias que tenemos sobre ella proceden de las obras que versiona (Angélico, 2001) y de la crítica que la prensa realizó al día siguiente de su estreno. En el programa de mano se lee que la pieza tiene un objetivo político y moral, y está concebida como una réplica a la tesis de Jefim Sosulia en su cuento «Ak y la humanidad».

Este cuento fue editado en Madrid por la editorial Zeus en 1930 en el volumen titulado Escritores de la Rusia revolucionaria. Veinte cuentistas de la nueva Rusia, en versión de V. Orobón Fernández. Con idéntico argumento, la escritora Halma Angélico -seudónimo de María Francisca Clar Margarit- escribió su adaptación teatral, que fue estrenada en septiembre de 1938, en plena Guerra Civil, en el teatro Español. La obra despertó tal polémica y ataques contra su contenido y su autora en la prensa anarquista y socialista que a los nueve días de su estreno fue suspendida por orden gubernativa. Aunque la crítica de $A B C$ fue benigna con la obra, la de C.N.T, órgano de la Confederación Nacional del Trabajo, en la que militaba Halma Angélico, la tilda de contrarrevolucionaria, pueril y desdeñable. Y la crítica política se extiende a los pocos días a El Sindicalista, La Libertad y El Heraldo que le reprochan la torpeza de su desenlace. Se trata de una distopía sobre el mejoramiento de la especie humana y la búsqueda de un mundo perfecto mediante el suicidio y eliminación de quienes física o moralmente sean imperfectos. El argumento que la obra de Ayesta y Crespo retoma es el siguiente en el resumen del $A B C$ :

En una sociedad cualquiera, nos presenta a un hombre -Ak-investido de poder omnímodo sobre sus compatriotas, que decide poner en práctica la sublime idea de un mañana perfecto. Para ello, psicólogos y médicos, constituidos en Tribunal Supremo, examinarán, uno por uno, a los ciudadanos, fallando cuáles son los que merecen seguir viviendo, y quiénes, considerados superfluos, han de desaparecer, eliminarse, en veinticuatro horas. Pero cuantos 
más mueren, mayor es la duda de Ak sobre la justeza del camino emprendido. «Al estudiar detenidamente a los vivos - dice- se saca la consecuencia de que las tres cuartas partes deben desaparecer, y al pensar en los muertos no se sabe si lo cierto hubiera sido amarlos y compadecerlos». Entonces intenta probar a redimir a los humanos por la bondad, por la comprensión mutua, por la creación de un Tribunal de la Tolerancia, encargado de hacer fácil y alegre la vida a todos. Pero sus súbditos se muestran quisquillosos, mal educados, violentos... Y Ak desaparece un día -tras volver a cruzar por su mente la idea de que la salvación está en la muerte-, dejando a la pobre Humanidad irredente, entregada a su destino. ${ }^{25}$

Los autores de La ciudad lejana dicen haber tenido en cuenta tanto el cuento ruso como su adaptación teatral española: «De ambas hemos tomado lo que nos pareció inútil y lo excesivamente sectario o demagógico». La obra, dice el programa, es de sobra conocida por todos: «Jefim Sosulia llega en su cuento a una solución nihilista que nosotros de ninguna manera podemos aceptar» y por ello es misión para el TEU -en general- poner en escena su réplica.

Por lo que nos cuenta la crítica, la obra de Ayesta y Crespo reproduce el argumento de Ak y la humanidad, si bien, por lo que podemos apreciar, añade un final diferente en el que parece notarse un cierto espíritu de astracanada, al menos en la descripción de Alfredo Marqueríe para el $A B C$ : Una joven de abrigo ancho y gran cinturón convence a Ak de salvar a la humanidad y va poniéndoles lacitos rosas. Pero cuando Ak los ve inútiles, entregados a las novelas rosas, se arrepiente. El final de la obra seguiría con ese mismo toque de Arniches o Valle-Inclán, y en lugar de la decepcionante desaparición final de Ak -de la versión de Sosulia y de Angélico-, Ayesta y Crespo le dan un final distinto:

Después [Ak] rectifica su benignidad y concluye que todos son imbéciles y les invita a partir con él al desierto para llamar con nombres nuevos a las cosas. Los personajes que quedan en escena, y que simbolizan en cierto sentido -muy amplio, desde luego- el coro de las antiguas tragedias, tocan todos una trompetilla de cotillón y de verbena que surgen misteriosa y simbólicamente. Y cae el telón (31-5-1944).

Así como la representación del entremés cervantino mereció que el telón se levantara varias veces para que los actores recibieran los entusiastas aplausos de los espectadores, Marqueríe condescendientemente añade que el público también aplaudió la que llama «desconcertante réplica».

25. Sobre la polémica que despertó la versión teatral de Halma Angélico en la prensa española, remitimos a la edición de Doménech, que incluye ambos textos y a Pedro Cataslán (2008). 
Sin embargo, Arriba dice que fue una obra muy aplaudida y le ve una profundidad de pensamiento que el anterior crítico no señalaba: «sobre la posición materialista del cuento primitivo que pretende superar a la humanidad fuera de toda creencia y posición sentimentales, [los autores] oponen la salvación por el espíritu, elevando la poesía y el corazón por encima de la opinión sectaria y demagógica (31-5-1944). Jorge de la Cueva, en su crítica del Ya, incluso le da el titular de la representación a la obra de Ayesta y Crespo, en lugar de dárselo a Cervantes: «La ciudad lejana, comedia dramática de Alberto Crespo y Julián Ayesta», subrayando en su crítica que al desenlace amargo y desperanzado del ruso, los españoles logran darle un final optimista, aunque también menciona una cierta inexperiencia teatral en el perfil de Ak y en el desenlace (si bien, ambos defectos proceden de las versiones anteriores). Como en la versión de Angélico Halma, el final es tan rápido que nadie se esperaba que cayese el telón e hizo deslucir la expectación creada. En Informaciones, C.E. también centra el titular en La ciudad lejana que, en general, ha resultado una obra «interesante». Si bien el público puede estar ya de vuelta en lo relativo a las disquisiciones sobre un gobierno justo, la obra ha sido un proyecto noble, aunque con «inocentes conclusiones espectaculares». Sin embargo, repite que fue una obra interesante y que el público la aplaudió con entusiasmo. Madrid brevemente anota la pretensión simbólica y poética de la obra y una cierta confusión entre los espectadores que, no obstante, aplaudieron su ambición.

\section{El farsante del mundo occidental}

En 1947, Julián Ayesta realizará la traducción de esta obra de John Millington Synge, en colaboración con sus amigos Rafael Montesinos y Charles David Ley. La obra había ocasionado en su estreno en Dublín de 1907 una gran polémica por el asunto que trataba: un parricida, embaucador y atractivo, que para la crítica y espectadores fue una ofensa a la moral y costumbres irlandesas.

Cerca de la tertulia a la que acudía Ayesta en 1947, se reunía el grupo teatral del TEU, en torno a su director Modesto Higueras. Así nos lo cuenta en sus memorias Charles David Ley, quien comenta que de vez en cuando representaban los domingos en el Español o en otro teatro, alguna obra clásica. Al comentario de Modesto Higueras de que Lorca era su maestro y que se había interesado por el irlandés Synge, autor de Jinetes hacia el mar, Ley añadió que Bodas de sangre y Yerma tenían el mismo ambiente y valores poéticos del habla campesina apreciables en la obra del irlandés, ya entonces traducida por JRJ y Zenobia Campubrí. A ello le respondió Modesto Higueras que una de las ilusiones de Lorca era poner en escena El farsante del mundo occidental, por lo que animó a Ayesta, Montesinos y Ley para que hicieran una versión: 
Infelizmente, cuando estaba hecha la traducción las autoridades responsables del Teatro Universitario se escandalizaron del tono de la obra y su presentación de los campesinos irlandeses como buenos paganos poéticos, cuyo catolicismo es completamente superficial. No me lo explicaron así, pero de todas formas era evidente que no había nada que hacer (Ley, 1981: 86).

De manera que esta traducción en que colaboró Ayesta no vio nunca la luz. Sí, en cambio, la que después realizó Ley en colaboración con Luis Castillo de Jinetes hacia el mar, que se representó el 29 de abril de 1947 en el Aula Magna de la Facultad de Letras y se repitió para el Teatro de Cámara del Teatro Español, parece ser que con la orden a los actores de que hablasen lentamente para compensar la brevedad de la pieza, ocasionando un fracaso total (Ley, 1981: 86-87). Pero el empeño de Higueras en El farsante no cejó, y finalmente pudo estrenarla bajo su dirección en el Teatro Nacional de Cámara y Ensayo en 1956, si bien, probablemente perdida la versión de Ayesta, Ley y Montesinos, la versión estrenada fue de Elías Gómez de Picazo (CDT).

Estas fueron las obras de Ayesta para el TEU, aunque su interés por el teatro se mantendrá como su gran vocación durante toda su vida. En los años cincuenta aún reseñará varias representaciones teatrales: desde La mordaza de Sastre o La viuda de las camelias de Álvaro de Laiglesia a las representaciones de Claudel, Lorca o el Don Juan Tenorio (Ayesta, 2003: 36-56). Cinco años después del rechazo de su traducción de Synge, hará una lectura dramatizada de su prometedora obra Entierro de caridad para la tertulia Hispanoamericana de Rafael Montesinos, que, según figura manuscrito por Ayesta en el texto inédito, también fue censurada. El fusilamento de los zares de Rusia será su última obra teatral publicada, aunque nunca representada (1967). Estuvo a punto de estrenar Estado de razón (1971), pero también será prohibida por la Junta de Censura Teatral. Y aún habrá que sumar a todas ellas varias obras teatrales inéditas, como La hija (1966), Diversiones nocturnas (s.f.), Clemencia (s.f.) y La drogadicta de Ámsterdam (s.f.) (Pau, 2003; Lázaro, 2013).

\section{Bibliografía citada}

A.M., «En El Español: Brillante actuación del T.E.U.», Informaciones, 9-6-1943. ANÓNIMO, «Muerte del niño fascista Jesús Hernández», ABC, 11-4-1934.

—, «Hoy, con el recuerdo vivo de Matías Montero, el Frente de Juventudes conmemora solemnemente en toda España el día del Estudiante Caído», $A B C$, 9-2-1943.

—, «Español: Función Extraordinaria por el Teatro Español Universitario», Arriba, 31-5-1944. http://teatro.es/estrenos-teatro/la-ciudad-lejana-7108/documentoson-line/prensa [consulta: 3 noviembre 2017]. 
—, «Los populares de 1968 según el diario Pueblo», La Vanguardia Española, 15-12-1968.

—, «Los "Populares" de Pueblo 1968», ABC, 17-12-1968.

AlOnso, Cuca, «Entrevista a Julián Ayesta», El Comercio, 31-8-1986, reproducida en Cuaderno Cultural Prímula, año 9, n 17, diciembre de 2013, pp. 18-20.

ANGÉLICO, Halma, Ak y la humanidad, ed. F. Doménech, Madrid, ADE, 2001.

ANGUlo, Julio, «La Universidad de Alcalá de Henares», Haz, nº 2, marzo de 1943.

AYESTA, Julián «La República. Memorias de un joven burgués», Haz, no 2, marzo de 1943.

—, «Simplemente así», Cisneros, nº 1, 1943.

—, «El tímido Serafín», Cisneros, n 4, 1943.

—, «Improntu para Masoliver», Garcilaso, nº 18,1944, s. p.

- «Entierro de caridad o El triunfo de la equidad. Primer acto», La Tertulia, $\mathrm{n}^{\circ}$ 3, 1953, pp. 32-44.

—, «La lengua reformada», ABC, 31-1-1954.

—, «El fusilamiento de los zares de Rusia», Mundo Hispánico, n 232, 1967, 63-69.

—, Tarde y crepúsculo, Pról. de Medardo Fraile, Madrid, Diptongo, 1993.

—, Dibujos y poemas, ed. de Antonio Pau, Madrid, Trotta, 2003.

-, Cuentos, ed. de Antonio Pau, Madrid, Pre-Textos, 2001.

-, Helena o el mar de verano, Barcelona, Akal, 2017.

BAjo MARTínez, Ma Jesús, El teatro universitario en Sevilla (1940-1970), Tesis doctoral del Departamento de Literatura Española de la Universidad de Sevilla, Dir: Juan Carlos Hidalgo Ciudad, diciembre de 2015.

C. [probablemente Cueva, Jorge de la], «Español: Función extraordinaria por el T.E.U.», Arriba, Madrid, 9 de junio de 1943, p. 13 < http://teatro.es/catalogointegrado/espa\%C3\%Blol-funcion-extraordinaria-por-el-t-e-u-1424496-3> [consulta: 5 noviembre 2017].

CASAS, Ana, «Julián Ayesta: narrador garcilasista», España Contemporánea. Revista de Literatura y cultura, T. 20, núm. 1, 2007, 63-86.

CARVAJAL, «Tipología del estudiante de Filosofía y Letras», Cisneros, 8, 1943, 5-6.

Castro Cubells, Carlos, «La Facultad de Filosofía y Letras», Cisneros, 4, 1943.

CATASLÁn GARCía, Pedro, "Ak y la humanidad: Una obra bajo sospecha», Teatro: Revista de Estudios Culturales / A Journal of Cultural Studies: Número 22, 2008, pp. 167-195.

C. E., Informaciones, 31-5-1944.

—, «El T.E.U. en El Español: Estreno de La ciudad lejana de Alberto Crespo y Julián Ayesta», Informaciones, 31-5-1944. <http://teatro.es/estrenos-teatro/la-ciudadlejana-7108/documentos-on-line/prensa > [consulta: 3 noviembre 2017]. CRESPO, Alberto, «A Cornelio Zalea Codreanu», Haz, nº 2, marzo de 1943. 
CUESTA, Janel, «De Somió a Cimadevilla. Julián, Luis y César Ayesta», El Comercio, 2 de noviembre de 2006; <http://www.elcomercio.es/prensa/20061102/gijon/ julian-luis-cesar-ayesta_20061102.html > [consulta 15 octubre 2017].

CuEVA, Jorge de la, «Teatro Español: La ciudad lejana, comedia dramática de Julián Ayesta y Alberto Crespo», Ya, 1-6-1944 <http://teatro.es/estrenos-teatro/la-ciudad-lejana-7108/documentos-on-line/prensa> [consulta: 3 noviembre 2017].

Entrambasaguas, Joaquín, Antología del alba (1940-1942), Universidad Central, Madrid, 1943.

FERNÁNDEZ Almagro, Melchor, «Julián Ayesta, prosista», La Vanguardia Española, 4-12-1952.

García Luengo, Eusebio, «El celoso por infiel», Haz, nº 2, marzo de 1943.

García Ruiz, Víctor y TORRES NebrerA, Gregorio, Historia y antología del teatro español de posguerra, 1939-1975, vol. 2: 1945-1950, Madrid, Fundamentos, 2003.

GÓMEZ García, Manuel, Un hombre de teatro. Modesto Higueras. El maestro y la asamblea, Madrid, Gráficas CARO, 2006.

GORDÓN, José, Teatro experimental español, Madrid, Escelicer, 1965.

GRACIA, Jordi, La resistencia silenciosa, Barcelona, Anagrama, 2004.

Huerta CALvo, Javier, «Los clásicos al servicio del nuevo régimen», Cuadernos de teatro clásico, no 22 (2006), pp. 32-33.

-, «Clásicos en la Universidad. Los TEU», Cuadernos de teatro clásico, n ${ }^{\circ} 22$ (2006), pp. 34-36.

IBÁÑEZ MARTín, José, «Palabras del Ministro de Educación Nacional», Cisneros, $\mathrm{n}^{\circ}$ 1, 9-I-1943, pp. 5-6.

JATO, David, La rebelión de los estudiantes. Apuntes para una Historia del alegre SEU, Madrid, Talleres Cíes, 1953.

LÁZARO, Juan, «Aproximación al teatro de Julián Ayesta», Don Galán. Revista de investigación teatral, $\mathrm{n}^{\mathrm{o}}$ 3, $2013<$ http://teatro.es/contenidos/donGalan/donGalanNum3/pagina.php?vol=3\&doc=2_2> [consulta: 16 octubre 2017] .

Laín Entralgo, Pedro, «Ideal falangista del hombre», Cisneros, n 1 , 1943, 1-3.

LEY, Charles David, La costanilla de los diablos. Memorias literarias 1943-1952, Madrid, José Esteban, 1981.

MADRID, Iván de. Informaciones, Madrid, 8-6-1943, p. 2.

MAINER, José-Carlos, Falange y literatura, Barcelona, Labor, 1971.

MARQUERÍE, Alfredo, Informaciones, Madrid, 9-6-1943.

—, «"La cueva de Salamanca" y "La ciudad lejana” en función extraordinaria organizada por el Departamento de Propaganda del SEU», ABC, 31-5-1944.

Montesinos, Rafael, Cuarenta años de la Tertulia Literaria Hispanoamericana. La memoria y el martes, Madrid, Instituto de Cooperación Iberoamericana, 1992.

O., «Teatro Español Universitario. Reposición de La cueva de Salamanca y estreno de La ciudad lejana, réplica dramática a una obra rusa», Madrid, 31-5-1944.

Anales, 29-30 (2018), pp. 133-160 
<http://teatro.es/estrenos-teatro/la-ciudad-lejana-7108/documentos-on-line/ prensa> [consulta: 3 noviembre 2017].

Ortega y Gasset, José, Obras Completas. Tomo II (1916), Madrid, Taurus.

PAleOlogos, Konstantinos, «Helena o el mar del olvido de Julián Ayesta y el canon

literario de la narrativa española del siglo XX», Actas del XVI Congreso de la Asociación Internacional de Hispanistas: Nuevos caminos del hispanismo... Coord. por Pierre Civil, Françoise Crémoux, Vol. 2, 2010, pág. 185-192.

PARRA GAlindo, Antonio, «Julián Ayesta, el último caballero», La Nueva España. Diario de Asturias, 11-8-2012.

PAu, Antonio, «Julián Ayesta. El resplandor de la prosa», en Ayesta, Cuentos, Madrid, Pre-Textos, 2001, pp. 9-119.

Perucho, Juan, «Nos dejó Julián Ayesta», La Vanguardia, 18-2-2002.

Pinillos, José Luis, «Los egoístas confiados», Alferez, nº 7, 1947.

Primo De Rivera, José Antonio, «Sentido heroico de la milicia», Haz, no 6 , 15-7-1935.

—, «Mientras España duerme la siesta», Haz, nº 8, 19-7-1935.

—, «La política y el intelectual: Homenaje y reproche a Don José Ortega y Gasset», $\mathrm{Haz}, \mathrm{n}^{\circ} 12,5-12-1935$.

RÓDENAS, Miguel, «Representación extraordinaria por el Teatro Español Universitario, en el Español», ABC, 9 de junio de 1943, p. 13.

SÁnCHEZ-BElla, Alfredo, «Nuestro colegio Mayor», Cisneros, núm. 1, enero de 1943, pág. 57-63.

UMBral, Francisco, La noche que llegué al café Gijón, Barcelona, Destino, 1977.

VILLACORTA, Juan Carlos, «El T.E.U. vuelve esta noche al Teatro Español», Arriba, 8-6-1943 <http://teatro.es/catalogo-integrado/el-t-e-u-vuelve-esta-noche-alteatro-espa\%C3\%Blol-1424494-3> [consulta: 1-10-2017]. 